\title{
Identifying paradox-governance model in NPO: A new cover for an old book?
}

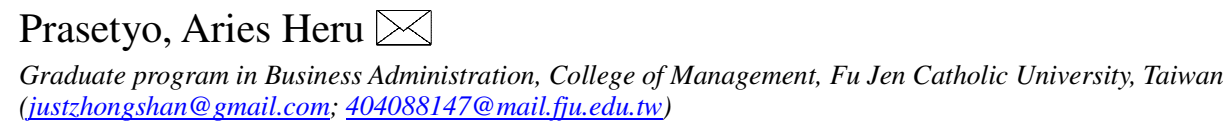

Received: 9 May 2018

Available Online: 5 July 2018
Revised: 22 May 2018 DOI: $10.5861 /$ ijrsm.2018.3012

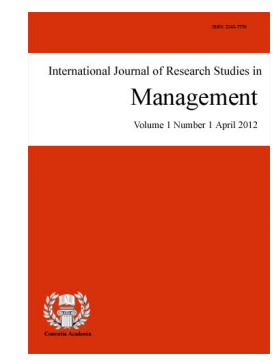

ISSN: 2243-7770 Online ISSN: 2243-7789

Accepted: 17 June 2018

\section{Abstract}

The study tries to examine the paradox-governance model through the applications of complex adaptive system. Aiming to provide clearer evidence, this study performs two years of participatory action research upon four religious-based educational foundations in Indonesia, Malaysia and Singapore. Four critical elements are carefully analyzed; how each board member develops the schemata, how these schemata are reinforced by external forces, how agents react with the edge of chaos while ended up with the coevolution process. As results, the study fails to recognize the proper applications of paradox-governance perspective along the four stages. However, the only possible way to recognize this model is by extending the phase up to the post evolution stages which requires two denominators: levels of democracy and organizational power to join the next evolution process. Four non-profit governance models are proposed: democracy-adaptive model, partnership model, board centric and bureaucracy model. Finally, the study affirms that for social organization, good governance is not limited to system procedures but more to human complexity, thus leaving clear spots for future works.

Keywords: governance; paradox perspective; complexity theory; nonprofit organization; democracy; evolution 


\section{Identifying paradox-governance model in NPO: A new cover for an old book?}

\section{Introduction}

What would be the most ideal governance model for nonprofit sector? This issue draws attentions from scholars for the past four decades. Multiple approaches have been deployed to derive the ideal and applicable model. One of the most popular methods is by adopting theories from commercial sector which first applied the concepts. Agency theory, stewardship theory, democratic perspective, stakeholder theory, resource dependency and managerial hegemony theory are amongst popular concept that has been well adopted. However, analyses on those theories are only feasible for academic purposes and not so for the practical matters. Today more researchers believe that organizational governance is close to human- related matters rather than sets of systematic procedures. If this holds true then organizational governance is truly about human behavior and how they interact each other - for example between shareholder and manager (as refers to agency theory), internal and external parties (as refers to resource dependency) or even between management and organizational stakeholder (as refers to stakeholder theory).

Among the current explanations, one logical perspective is offered by paradox-governance theory which is proposed by Chris Cornforth (2004). In this perspective, non-profit governance is treated in a similar way with the good corporate governance. Through the proposed logic, a good non-profit governance is believed as contractual mechanism which places both sides at the same platform. Thus, common tactics such as financial benefits, comprehensive salary and bonuses shall be useful to perform the mechanism. Up to that point, the generalization of the model is somewhat absurd since NPO is a resource-dependence entity (Bernstein, Buse, \& Bilimoria, 2016; Alexander \& Weiner, 1998). Therefore, resolving these absurdities must begin from behavioral perspective of the board member.

A closer analysis to the board's role - in their human complexity, concludes that good understanding regarding the tension between mature theories may lead us to formulate the most productive governance mechanism for NPO. One cannot demise that the board consists of unique humanistic character who - through democracy system - are trying to perform their roles upon agreeable terms. Focusing more on the process of how different interest is created, the previous works overlook the occurrence of transactions of prominence as results of the complexity from the adopted democracy system. On that essence, this study tries to disentangle some unobserved phenomenon using complexity theory.

The study begins with observing board's role as nonlinear behavior. Drawing back from Hart and Quinn (1993) which then developed further by Westphal (1999), Carmeli and Halevi (2009) and also Van Ees and Gabrielsson (2009), complexity of board on its relations to organizational governance is derived from four competing roles: Vision setter, motivator, analyzer and task master. And uniquely, this complexity is relating to how each board holds their democratic leadership style. In organization with high levels of democracy, complexities of those four roles are more visible compared to those at the lower level. But that doesn't mean if the complexity may easily disappear. The humanistic factor tends to retain its level up to one moment when it may reveal itself on a higher level.

The most interesting part regarding the four competing roles is how board as an individual performs complex adaptive system (CAS). Now as the study derives the concept from organizational theory, complex adaptive system is characterized of four key elements: (1) agents with schemata, (2) self-organizing networks sustained by importing energy, (3) coevolution to the edge of chaos and (4) system evolution based on recombination. Puzzling combinations among the four factors can be learned from Schneider and Somers (2006), DeRue (2011) and also Obolensky (2014). To those previous authors, recurring patterns in leading the organization is happened randomly due to -what they might think as uncertainties. This is why scholars believe 
that paradox perspective is still useful in disentangling any grand phenomenon such as corporate governance.

Aiming to provide clear explanation to this topic, our study tries to examine twofold of questions.

$>$ First, how the four factors can explain the phenomenon of governance within nonprofit organization. This study uses participatory action research to four religious-based educational foundation in three countries. Series of in depth interview proceeds by proper information consent and field observation had been carry-out to find new insight to the observed theme. Through this method, the study tries to identify the unique form of governance which distinguishes its application for NPO and commercial sector thus proofing the existence or non-existence of paradoxical approach.

$>$ Second, what is the governance model that fits in with the given constraints from environment? A postulation of the governance model is then proposed as final conclusion and future research agenda.

The next section will provide some dialectics argument on two aspects: paradox-governance concept as well as complexity theory of organization. The study focuses on the reality of contra-interest which happens in almost every organization and how the board reacted to the given condition. Section three will explain every step taken to use the theory among the three unit of analysis. Section four will clarify all findings from the study and provide briefly discussion on how the evidence shares contribution to academic and practical knowledge. Several challenges are also portrayed in order to provide new insights to the body of knowledge. Meanwhile section five provides conclusion and suggestion for further works.

\section{Literature review}

\subsection{Paradox-governance perspective}

Research on paradox-governance perspective is rooted in Alexander and Weiner (1998). Using NPO as unit of analysis, former research identified that adoption of corporate governance practices depend on supportive institutional context. They tend to use all available resources to support the implementation of good governance, including values which being implemented by the society. That is the reasons why NPO must be able to adapt with democracy system of the communities. For society with direct democracy system, organization has to provide particular mechanism to accommodate such issue.

Another thought is coming from Suarez de Vivero, Mateos, and Florido del Corral (2007). Focusing on governance model for fisheries community, the author sees the growth of focal actors in the community is manifold as the results of democracy. Wider access for the actors to raise their opinion tends to increase the numbers of variety interests. A nonprofit organization that lives within certain condition must have the ability to work with all actors in order to accommodate their idea into practical basis. This idea is fully supported by Dunn-Cavelty and Suter (2009), and Berent-Braun and Uhlaner (2012).

On subsequent developments, this study identifies the loss of ideas to put democracy as a trigger to corporate governance. Most former researches had shifted to become adopters of governance from commercial sector. Moreover, as the study tries to summarize Jegers (2009), Speckbacher (2008), Renz (2007), Siebart and Reichard (2004), we found that adopting the concept from commercial sector is plausible to provide benchmark in analyzing nonprofit governance. However, four main challenges must be responded effectively. First is relating to the application of agency problem. A mutual trust between the board - known as representative of the stakeholder and the executive must be achieved in order to create a one-tone rhythm in terms of organizational culture. They believe that this is the fundamental power to gain a common interest over long term periods. At that point, scholars are querying whether the uniformity of action is needed by NPO to perform good governance.

Second is referring to stakeholder's perspective theory. Diversity of interest should be sees as manifold of 
varieties perspective from stakeholder. If this happen, NPO should play the roles as a good politician (i.e. balancing the required needs, designing policy which can accommodate all interests and providing a good control mechanism to ensure the objectivity of each policy and strategy). Hereinafter, some scholars see this challenge as too ideal to be solved therefore new thoughts are required to find better explanations.

Third challenge is due to resource availability. Drawing back from resource based view it is stated that formulating competitive advantage is not easy due to scarcity of resources. In fact, scholars had been struggling to pose good corporate governance as way to deal with this. Using this idea, it is common to justify the different between stakeholder and managers' point of interest. But thanks to democracy concept which leads the society to a higher level of appreciation to others needs and interest. Through better democracy system, everybody will refrain from taking action that harms others. As results, co-optation model has been defined as the best model to explain how governance mechanism may bring a new solution to the problem (Barney, Wright, \& Ketchen 2001; Barney, 2001).

Finally, the fourth challenge is relating to the adoptions of stewardship theory. As compared to the previous theories, stewardship perspective focus on how each party tends to bring noble thoughts relating to nonprofit organization. Begin with the understanding that every actor in NPO is not an agent but more to as stewards, the concept is then being developed in the essence that each contractual relationship should adhere the highest social norms (Bacq \& Eddleston, 2016, Bernstein et al., 2016, Van Slyke, 2006).

Diversity of perspective in how governance concept must be fully applied in NPO has lead Cornforth (2004), Harrow and Phillips (2013) and Dent Jr. (2014) to proposed new thoughts. A paradox-governance perspective is named for a new pathway to explore the most appropriate model for NPO. Instead of using theory in its stand-alone basis, scholars are now being encouraged to use a minimum of two theories to provide clear insight on the governance model. Starting with examining every particular weakness that existing theory had posed the authors explained that nonprofit sector must be sees as having unique character. At the same time they need to face multiple challenges begins with how to gain access to some resources, how create balances among existing interests, how to operate in the highest level of productivity and how to cultivate society's willingness to participate actively in the program. These facts require the applications of multiple theories. As to that point, upon a firm statement, Cornforth (2004) mentioned that the ideal governance model for NPO must consider the diversity of interest which had happened in the organization. A suggestion of the use of multiple models such as compliance model, partnership model, democratic model, stakeholder model, co-optation model and rubber-stamp model are proposed as the best solution for future works.

Conveying with the previous idea, it is important for us to consider how diversity of interest occur in the organization. This is the path in which bring us to series of works done by Alexander and Weiner (1998), Suarez de Vivero et al. (2007), Dunn-Cavelty and Suter (2009), and Berent-Braun and Uhlaner (2012). By constituting levels of democracy, we believe that this paper will be able to contribute more to the existing body of knowledge. Moreover, the use of behavior theory is needed to disentangle how types of democracy lead to cooptation of interest as trigger to the governance model. The next section will describe the premise using complexity theory.

\subsection{Complexity theory of corporate governance}

From the previous thought we had uplifts complexity theory to examine the ideal model of governance in NPO. The study first postulates that nonprofit organization is a complex unit that might experience a nonlinear behavior not only at the board levels but also from the stakeholder and managerial point of view. Different human character who is concerned with organization mission and vision has forced us to understand any complex adaptive system happened in the internal as well as external environment. Nonetheless, the study of complex adaptive system must encompass four key elements. The first is agents with schemata.

Now, let us refers to Holland and Miller (1991) which has been extended by Chiva, Ghauri, \& Alegre, (2014) and Mittal and Risco-Martin (2017). The boards must be defined as agents in our economy system, including 
when we use the term nonprofit organization. It consists of several peoples with varieties of mindset which comes from diversity of education, experience, and personal value, or maybe social and political preference. All these factors had created sets of perspective which influence in how they make preferences to choose the model of governance for the organization. Uniquely, there might be a schema in how each member of the board made decision. It can be a structured, unstructured or even a neural network. These fuzzy rules have made corporate governance as an evolving term. Once the rules had change, so has the schema.

Moreover, in creating those schemas, an individual must be examines upon the second terms: its self-organizing networks which sustained by importing energy - in most cases from external party. This is the point in which considering democracy in organizational governance becomes very important. Agents are partially related to one another. As a result, idea exchange under organizational dynamism system had acts as a systemic system that influences the behavior of agent. So that in general, they will act uniformly.

Referring to complex adaptive system, the study believes that this condition happens as the feedback loops within the board performed effectively. Everyone use the feedback as behavior-correction to be adaptive to others. At this point, we found signal the needs for a proper knowledge management system.

Now as the loops continue to performs, indirectly agents coevolve with one another. This has inserts the third elements: coevolution to the edge of chaos. Every agent in the board try to adapts to the environment by increasing their levels of fitness over time. However, such coevolution is dynamic. This is why some chaotic equilibrium might happen. But through their dynamic capability, the new equilibrium will keep on created so they can pass the chaos.

The coevolution is a long time process. As we consider the possibility for board's turnover, there comes the fourth element: recombination and system evolution. Putting organization into human behavior analysis, the coevolution provides interconnectedness among board's member. By bringing in their past experience, new member will automatically develop their interdependencies among other. On the contrary, member who is resigns from the board will act the same in their new organization.

A deeper analysis on the previous pattern, we may see that it is the rule that make agent try to follow a certain path. And again, it is only rules that well be inferred from behavior of each member of the board. Up to this point, the second premise may pose: in the organization with higher level of democracy, supported by productive knowledge management system, the governance evolution tends to improve the levels of expertise among board member. This is fundamental aspect for nonprofit organization to develop themselves to be the value enhancer for the society.

Using two-years of participatory action research, this study tries to analyze how complexity theory can provide better explanations in examining governance phenomenon.

\section{Research method}

This study consists of three major parts. First, six months of data collection including three times of focus group discussion among related stakeholder has been done. We focus on identifying all concerns to portray the diversity of stakeholder's interest. Three-rounds of FGD were performed to gain insights from variety of stakeholder, including to the on duty boards as well as retiree member. Furthermore, the third-rounds had been used to present all identified concerns and provide categorization on several governance-related matters. A comprehensive mind-mapping is also used to find the interconnectedness among problems.

All collected data are then being analyzed using paradox-perspective to identify (1) the levels of democracy which had experienced by the organization, (2) variety of interest as results of democracy, (3) what theory underlie the specified conditions. We ought to choose the most ideal theory that may represent the reality (i.e. agency theory, stakeholder perspective theory, resource availability theory and stewardship theory). Series of 
interviews are being performed to some of board members ( 6 members), donators ( 9 volunteers) and religious authority as the owner (1 leader). In this stage, we try to identify whether paradox perspective can be used in analyzing the phenomenon. Furthermore, to provide better analysis, we deploy complex adaptive system to look for the dynamic schema along the process. This is including the observations on four respective elements in complexity theory. A proper documentation and coding had been applied for future analysis.

Once the loops had been identified, we then provide two-round workshop on good governance concept and twelve months mentoring process to observe the system evolution. Along the process we succeed in witnessing how the evolution system happened due to member's turnover, thus presenting the whole idea about the theory.

\section{Findings and discussion}

\subsection{Convincing the stakeholder}

The study begins the overall process with identifying symptoms which leads us to the core problem. Two-round of focus group discussion had been performed effectively. At the first round, twelve attendees had participated the discussion (six board members, two Church representative and four management staffs). Lasting for more than three hours, we focus on identifying all internal concerns relating to the implementations of good governance. Our impressions are one three pivotal facts. First, among the six board members, different levels of understanding are easily portrayed. Four of them had been serves the foundation more than eleven years, leaving the two as new comers. During the discussion, the new member of the board seems to take good governance concept as a very important thing. Meanwhile, the other sees organizational governance as government-compulsory mandates. We then identified the reality as the first mission: enhancing the levels of understanding related to good governance mechanism.

Secondly, diversity of interest has been showed by the religious representative (as the owners), the boards and also from managerial perspective. We pointed out that the owner poses long term sustainability in terms of mission. The needs to define the foundation as bearing the responsibility of missionary are very strong. The owners even emphasize the importance of the foundation to serves more cities and provinces in order to reach out to the society as their ultimate targets. On contrary, the board sees resource-shortage as the main problem. Therefore, from their stands-point, it is clearly observed that every member in the boards is trying to achieve the highest performance during their service period. Careful and diligent in making a decision become a major factor which further justified as agency problem.

Thirdly, exploring the best motives from managerial perspective, the study found urgency to manage the overall performance through stewardship theory. Most of the manager emphasize that they share responsibility to develop the organization. Moreover, they valued their working activities as God's calling unto their lives. The three important issues are then being validated to the second round of discussions.

At the second round of FGD, 14 attendees participated the event. Among those number, 9 participants are donators, meanwhile 5 representatives from the government sides. Lasting for about two hours, the discussion emphasizes the importance of improving accountability and transparency in overall management schemes. Five skeptical points had been justified: (1) the importance of extending the definitions of accountability. Along the years, the foundation has valued as having the best accountability in terms of financial resources. But considering the needs for productivity, as a NPO, the stakeholder demanded that the organization must be able to stress on the outcome of their nurturing process. These two issues reminded us on the vital steps in redefining the service-based operation of the foundation. (2) The second skeptical point is relating to the pluralism of those being serves by the foundation. This is the challenge in which the religious-based organization is faced with the demand to serves other communities. By uplifting the needs of surrounding society, the two representative of society's management team urges the foundation to start giving a greater influence to solve a certain social problem. At this point, we believe that complexity theory may be useful in analyzing the phenomenon. (3) The 
third issues raised by majority of donators. A demand for future financial independencies had profound to be a pivotal concern. Having consider the growth of foundation that use the similar concept has made donators to distribute their resources in a fairly basis. This means that in the near future, they will not allocate their resources on one particular social movement. Moreover, from corporate social responsibility stand-point, diversity in resource allocation has leads the company to earn beneficial tax matters. Will this matter convey our system to experience an evolution? We noted this concern in our analysis.

Now, by highlighting on governance issue, one big problem is due to board duality phenomenon. (4) The fourth skeptical problem comes from the new live styles in developing country. A high-end society tends to use their position as the board members in social organization as self-actualization. Surprisingly they eager to fill the position in numbers of organizations thus are raising the problem of duality. Well, if we accommodate this issue as from stakeholder perspective, then organizational governance must have firm mechanism to deal with unfair treatment due to duality phenomenon.

The fifth skeptical issue is relating to the long-term function of the foundation. For years, this type of foundation is dedicated to deal with general human-competencies matters, but for the past four years, the four foundations start to induce the idea of social-entrepreneurship. As the foundation tries to solve any social problem, entrepreneurship know-how may be benefited to prepare their economic independence once they reach the age of adult. It's like providing long-term solutions for the student. If this is true, then redefinition and most probably rejuvenation in mission and vision statement is needed by the organization. All portrayed concerns are summarized in Figure 1. The size and its closeness to the core circle (concerns on governance system by NPO) represent the urgency of matters posed by the informants. Meanwhile the blank circles are representing the unspoken opinion. We will explore further at the third-round of FGD. On this round all participants from the first two-round attended the event to discuss some early findings.

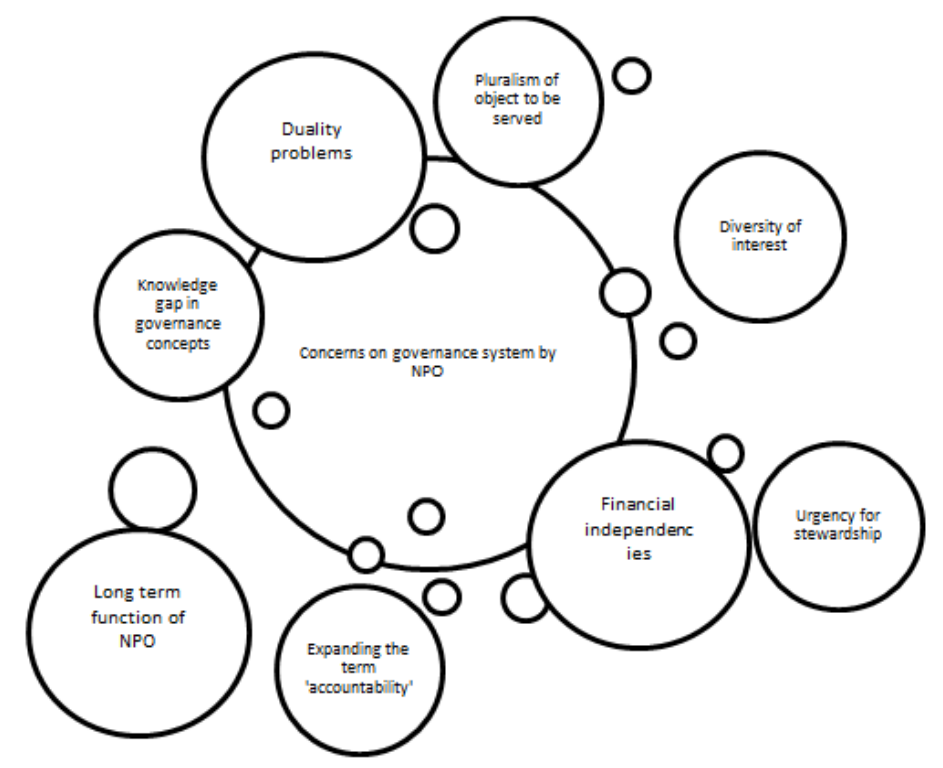

Figure 1. Stakeholder's concern on the governance system of the NPO

Source: Author's findings and conceptualizations.

\subsection{The spirits of democracy}

Upon the third focus group discussion, to each group, we present the eight concerns in order. After that, we spare time to provide opportunity to each party to raise their opinion. Without any dictate direction from researchers, each party naturally takes turn to pose their original opinion. When one participant speaks-out, the other give their full attention. This is the first signal to address the spirits of democracy. Furthermore, we witness 
the smooth process of democracy including effective communication and dialogs among party. After internal concerns have been discuss, there comes opinion from external-related party. At this time forward, the fifth skeptical concerns considered quite offensive. But in general, internal parties seem carefully listen to and try to accept the idea in objective ways. To us, that would be the second clues for more conducive democracy atmosphere owned by the society.

Supported by statement below, we confirm the use of democracy in alleviating stakeholder's voice to the organization. Furthermore, we try to offer some meaningful questions to examine whether the democracy spirits occur in a natural way or being forced by external power such as government policy. Four out of six board members mentioned clearly that the mechanism is a given condition which they carry-on from the previous generation. This is convinced by some supporting written documents relating to organizational policy. One document explains organizational culture in details that includes how democracy system must be enhanced.

"As the boards, we need to carefully examine the idea and opinion from stakeholder because they share their interest to this organization. They have rights to pose their idea which creates another obligation for us. Any failure in pursuing their dreams may result in negative image to the entire organization" - 52 years old experts with 11 years of experiences in the board.

As point to that, the board also highlights the role of democracy in creating a harmony in performing the governance policy. Based on the corporate credo, it is evidenced that the organization tries to put every member of the board at the similar position - there is difference between senior and junior member. The equality spirits tend to direct the democracy process up to its limit. Everybody use to see their roles as self-devotion to the noblest state of art.

"In line with our organizational philosophy, every member must able to face diversity in opinion or idea. Because we believe that everyone - including the stakeholder always give their best efforts for the organization" - 55 years old professional with 10 years of experiences in the board.

Up to this point, the study witnesses how spirits of democracy is being implemented in the four organizations and how it contributes to the way the boards hold their governance mechanism. At the next section we will provide comprehensive analysis on how paradox-perspective might useful to formulate the most ideal model. Using complexity theory through complex adaptive system the study has put its effort to pose new idea for future agenda.

\subsection{How complexity theory provides access to unseen phenomenon of governance}

Referring to Dent (2014) and DeRue (2011) the applications of complexity theory in our study is focus on complex adaptive system. We begin with defining the term 'system'. In accordance with the purpose of this study, we set the system as organization's governance mechanism. It consists of organizational structure, governance policy and procedures and also the agents (i.e. the board members). After setting the area of analysis we begin to deploy four elements of complex adaptive system to analyze how paradox-perspective might useful to examine the governance phenomenon in NPO. Below are details of our finding.

Agents with schemata - The first element in our study is agents with schemata. As complimentary to all previous works done by Jones (1987), Bushman Chen, Engel, and Smith, (2004) and Ebrahim, Battilana, and Mair, (2014), in this study we try not to show the dichotomy of organizational infrastructure and the role of human in the context of governance. We believe that by doing so, we will be able to use complexity theory in relevant ways.

Our study acknowledged organizational governance as sets of paradigm, policy, strategy and envisioned people which strive to bring the organization as the center of stakeholder's interest. Using participatory action 
research, we work closely with the board member through three big projects. First is providing series of workshop and discussion regarding organizational governance strategy. The objective of this step is to portray the schema used by all agents to perform their collective behavior. At the first workshop, we precede the session with analyzing board's perception of governance concept. Again, with spirits of democracy, everyone raises their opinion. We use mind-mapping software to describe the schema - as seen on Figure 2.

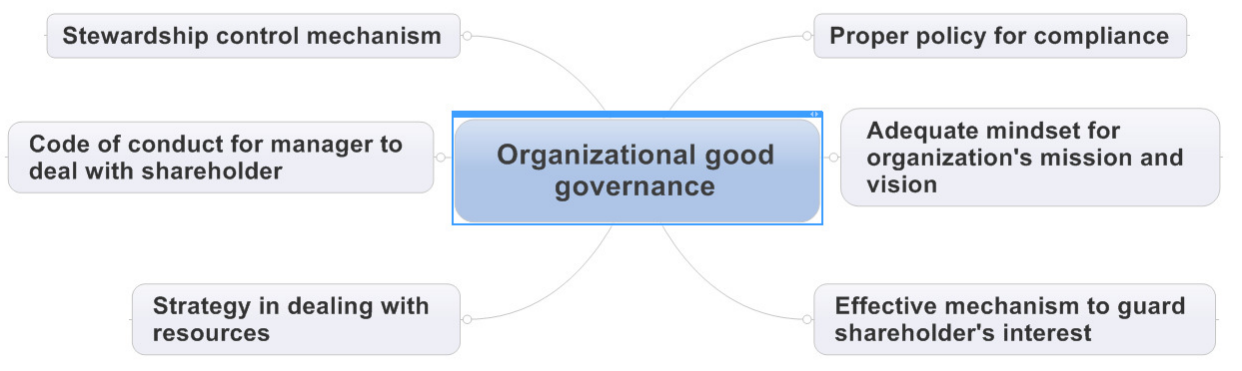

Figure 2. The preliminary mindset

Source: Author's findings and conceptualizations.

Unconsciously each opinion is actually representing the fundamental knowledge of organizational governance. Please refer to Figure 3 to identify the schema used by the boards. It is clear that each opinion is based on everybody past experience in understanding what organizational governance is. From Figure 3 , we can see that almost each member has their own paradigm in seeing one particular concept. And this provides evidence that the organization had never been posing efforts to design their original definition instead of using other current knowledge. This is dangerous since adopting the concept from commercial may harms the true character of becoming nonprofit oriented.

We put more concern to the use of 'compliance'. In the context of NPO, we believe that the agency problem must be solved before new members joined the board. As mentioned by Ebrahim et al. (2014) followed by Schnackenberg and Tomlinson (2016), nonprofit organization must be sees as unique entity which doesn't require complex problem at the infrastructure level. Uniformity to elevate the overall performance must be achieved effectively. Therefore, compatibility among mission and vision is the fundamental requirement to join the movement.

\begin{tabular}{|l|l|l|l|}
\hline \multicolumn{1}{|c|}{ Concerns } & \multicolumn{1}{|c|}{ Identified schema } & \multicolumn{1}{|c|}{ Reference theory } & \multicolumn{1}{c|}{$\begin{array}{c}\text { Prospective } \\
\text { governance model }\end{array}$} \\
\hline Compliance & Shareholder > manager & Agency theory & Agency model \\
\hline $\begin{array}{l}\text { Adequate } \\
\text { mindset }\end{array}$ & $\begin{array}{l}\text { Stakeholder }>\text { owners }> \\
\text { managers }\end{array}$ & Organization theory & $\begin{array}{l}\text { Democracy-Adaptive } \\
\text { model }\end{array}$ \\
\hline $\begin{array}{l}\text { Stakeholder } \\
\text { interest }\end{array}$ & Stakeholder > managers & Stakeholder theory & Stakeholder model \\
\hline $\begin{array}{l}\text { Resource } \\
\text { constraints }\end{array}$ & $\begin{array}{l}\text { Available access to } \\
\text { resources required } \\
\text { resources }>\text { Resource based view }\end{array}$ & Co-optation model \\
\hline Code of conduct & $\begin{array}{l}\text { Organizational mission, } \\
\text { vision pattem of desired } \\
\text { behavior and thoughts }\end{array}$ & $\begin{array}{l}\text { Managerial hegemony } \\
\text { theory }\end{array}$ & Bureaucratic model \\
\hline $\begin{array}{l}\text { Stewardship } \\
\text { spirits }\end{array}$ & $\begin{array}{l}\text { The highest ownership of } \\
\text { the organization }>\text { self- } \\
\text { awareness }>\text { self- } \\
\text { actualization by all } \\
\text { stakeholder }\end{array}$ & & Partnership model \\
\hline
\end{tabular}

Figure 3. The schema, underlying theory and prospective model 
Drawing back from the previous thought, we urge to hold workshop to stimulate what is governance model and its applications in social-oriented organization. After presenting some new insights, the study witnesses how each agent is then get together to think as closed network. However, this is the signal to use the second element in our theory.

Self-organizing networks sustained by importing energy - At this second element, we (as researcher) positioned ourselves as the imported energy. Before holding the sessions, we are provided with strong knowledge on good governance through benchmarking process unto several successful organizations. Then, we are trying to bring new insights (which we call an imported energy) consists of (1) the extended definition of organizational governance which highly fits with NPO, (2) the importance to achieve uniformity (in general) without deletion of individual contra opinion (as results of democracy system) and (3) the critical point to have mutual agreement on how governance mechanism must be fully performed in the organization. As an attempt to provide times for the boards to discuss internally, we spare two days for them to reach the final decision.

During the process, we evidenced how the boards act as mutual network and enlighten by our imported energy. The proposed extended definition on organizational governance is then accepted by the boards. Surprisingly, they also come up with emphasizing the spirits of stewardship in interpreting good organizational governance. Moreover, they also claim to bear the responsibility to share the concept to all respective stakeholders. This is the point where we ended up the paradox-perspective governance model and continue with stewardship theory.

Although everything seems clearly acceptable, we still believe that at the notions of democracy, freedom for speech and voice, it's not easy for every member to accept the new idea. So we decided to carefully analyze the coevolution stage when they adapted to the new paradigm. We will explain this step at the next section.

Coevolution to the edge of chaos - From the beginning of this study, we believed that the behavior of board members in developing culture of governance for the organization is rooted from their nonlinear behavior in dealing with one another. Using bounded rationality theory by March and Simon (1958), we presume that agents are being clustered naturally due to their affirmative idea. But once there came a mutual agreement among themselves, each of them will escalate their fitness among one another. The previous landscape of mind will try to adapt through continuing shifting process to fully respect others opinion.

Our observation goes to the twelve months of couching and mentoring process upon the two (out of four) foundations. As the board has decided to uplifts the stewardship perspective, most of the member tries to use the paradigm in the discussion on series of formal meeting. For the first four months of implementation, we witness how contra-argument has dominated the meeting. It shows how each agent is trying to experience the coevolution in their togetherness to receive new paradigm. Furthermore, the study recorded one meeting defines as the chaotic stage of the process. It is the time where most members of the board find it difficult to raise the spirits of stewardship especially due to duality problem. Some believe that duality must be sees as embodiment of stewardship, whilst other still stands on the first place. Calls for interruption happen several times. Not only that, they also perform one focus group discussion by inviting more stakeholders.

As result, again, the stewardship theory has been totally affirmed. We mark this stage as the success of organization in passing the coevolution in terms of chaotic environment. Next step is examining the system evolution.

Recombination and system evolution - From the previous stage we find the evidences on how each member is actually acting as an adaptive system. Once - in general - they become more adaptable to others then we may conclude that recombination among complex adaptive system is successfully done. As we marking the final round of the study, we pose independency of the board in making governance-related strategic decision while taking positions as an observer. Through some invitations, they involve us in the meetings. Surprisingly, each adaptive cluster tends to grow by inserting newly advanced concept on stewardship theory. Through open 
communications (as results from democracy system which being adopted by the organization) each cluster learns from other. This time, we witness on how the tensions in democracy system has a great influence on the system evolution. Stakeholder's forces to implement stronger levels of democracy tend to influence the way the board prolong its governance mechanism. Using Singapore as settings, the coevolution process might happen through a productive collaboration among board and their respective stakeholder. Moreover, public control becomes more effective through the use of social media.

On contrary, in the context where NPO must operate under low control from the stakeholder, the choice of governance is based on how organization implements their democracy. Our observation shows that for NPO with stronger democratic level, the style of organizational governance is resting on the adaptive process towards every interest. Non-profit governance is implemented to ensure that every stakeholder will meet its interest. The evidence is quite clear; every time the foundation has to change the overall direction of curriculum they need to have consent from their respective stakeholder. However, for those with lower democratic level, the mechanism tends to concentrate on the bureaucratic system. Within these settings, NPO tends to use multiple layers of management as a filter for every available interest. As to that point, organization will consider every interest which is in line with the overall direction.

\subsection{Proposed model for future evolution}

Now as the organization evolved, so is the democracy among society. Our study had witnesses how imported energy in forms of new knowledge and insights are useful for the NPO to grow in terms of good governance. Using short scenario analysis and inspired by the previous works, we propose ideas for future works as seen on Figure 4. Linking the levels of democracy and the agent's power to perform evolution, there are four possible models (as refers from Figure 3).

\begin{tabular}{|c|c|c|c|}
\hline \multirow{4}{*}{$\begin{array}{l}\text { Levels of } \\
\text { democracy }\end{array}$} & Strong & $\begin{array}{l}\text { Democracy- } \\
\text { adaptive model }\end{array}$ & $\begin{array}{l}\text { Partnership- } \\
\text { governance } \\
\text { management } \\
\text { model }\end{array}$ \\
\hline & Low & $\begin{array}{l}\text { Bureaucratic- } \\
\text { govemance } \\
\text { model }\end{array}$ & $\begin{array}{c}\text { Board centric } \\
\text { model }\end{array}$ \\
\hline & & Low & Strong \\
\hline & \multicolumn{3}{|c|}{ Power of evolutions } \\
\hline
\end{tabular}

Figure 4. Models for future evolution

Source: Author's conceptualizations.

The first model - democracy-adaptive model, rests on the concept that in dealing with strong levels of democracy, the board must have the capacity to highly appreciate every available interest. Therefore, the key point would be on how they might easily have adapted to new settings. An effective communication process is needed to prolong this model. One vital benefit from this model is that the NPO may become the value enhancers for their society which allows them to shift to a stronger power of evolutions. Once the society tends to have better motivation to perform another evolution, they might become the true strategic partner of the NPO to prolong its governance mechanism. Moreover, the stakeholder will hold the function as productive counter party.

Different from the previous two models, the third model - board centric, rests on the idea that due to a low level of democracy, the stakeholder tends to rely more on the role of the board. This is where most of public figures hold the board position within the social organization. Although it is too premature to justify the rhetoric phenomenon in this context but we can use the model in positive matters; in which NPO might performs as 
social conductor towards new civilization. However, for a matured society, the power of evolution might somewhat low. This is the point in which NPO must use proper bureaucratic system to filter every available interest. The purpose of this action is to ensure that the overall direction remain in the agreed path.

We believe that the model is still debatable therefore deeper analyses are needed for future validations. Finally, our study provides proper evidence that using complexity theory through complex adaptive system, it's difficult to draws the fact regarding a proper use of paradox-governance perspective. The only stage that has the possibility to apply paradox theory is at the post evolution phase. This is to mark a new development level for organizational governance.

\section{Conclusion and further directions}

Using four religious-based education foundations as cases, the study tries to apply complex adaptive system to disentangle the existence of paradox perspective in portraying organizational governance mechanism. The analyses on four respective elements in the theory failed to find the appropriate use of paradox-perspective. But an extension of the study which describes the evolution power of the organization at the levels of democracy success to address the perspective. As results, four non-profit governance models are proposed: democracy-adaptive model, partnership model, board centric and bureaucracy model. Future research might be directed to provide an empirical insight to the proposed model.

For management studies, the paper provides comprehensive views on non-profit governance. It enhances the current thoughts by embracing the importance of organizational democratic system and the power of evolutions from the society as two vitals denominators in designing the governance model. Hereinafter the paper promotes the used of organizational characteristics in designing the model rather than adopting the model from the profit sector. As for practical matters, the study emphasizes the good governance as the product of democracy and willingness of the society to change thus, posing non-profit governance as the main mechanism in developing future civilization.

\section{References}

Alexander, J. A., \& Weiner, B. J. (1998). The adoption of the corporate governance model by nonprofit organizations. Nonprofit Management and Leadership, 8(3), 223-242. https://10.1002/nml.8302

Bacq, S., \& Eddleston, K. A. (2016). A resource-based view of social entrepreneurship: How stewardship culture benefits scale of social impact. Journal of Business Ethics, 10(1), 1-7. https://10.1007/s10551-016-3317-1

Barney, J. B. (2001). Is the resource-based view a useful perspective for strategic management research? Yes. Academy of Management Review, 26(1), 41-56. https://10.5465/AMR.2001.4011938

Barney, J. B., Wright, M., \& Ketchen D. J. Jr. (2001). The resource-based view of the firm: Ten years after 1991. Journal of Management, 27(6), 625-641. https://10.1177/014920630102700601

Berent-Braun, M. M., \& Uhlaner, L. M. (2012). Family governance practices and teambuilding: Paradox of the enterprising family. Small Business Economics, 38(1), 103-119.

Bernstein, R., Buse, K., \& Bilimoria, D. (2016). Revisiting agency and stewardship theories. Nonprofit Management and Leadership, 26(4), 489-498. https://10.1002/nml.21199

Bushman, R., Chen, Q., Engel, E., \& Smith, A. (2004). Financial accounting information, organizational complexity and corporate governance systems. Journal of Accounting and Economics, 37(2), 167-201.

Carmeli, A., \& Halevi, M. Y. (2009). How top management team behavioral integration and behavioral complexity enable organizational ambidexterity: The moderating role of contextual ambidexterity. The Leadership Quarterly, 20(2), 207-218. https://10.1016/j.leaqua.2009.01.011

Chiva, R., Ghauri, P., \& Alegre, J. (2014). Organizational learning, innovation and internalization: A complex system model. British Journal of Management, 25(4), 687-705. https://10.1111/1467-8551.12026

Cornforth, C. (2004). The governance of co-operatives and mutual associations: A paradox perspective. Annals 
of Public and Cooperative Economics, 75(1), 11-32. https://10.1111/j.1467-8292.2004.00241.x

DeRue, D. S. (2011). Adaptive leadership theory: Leading and following as a complex adaptive process. Research in Organizational Behavior, 31, 125-150. https://10.1016/j.riob.2011.09.007

Dent, D. W. (2014). Corporate governance without shareholders: A cautionary lesson from non-profit organizations. Journal of Corporate Law, 93, 93-114.

Dunn-Cavelty, M., \& Suter, M. (2009). Public-private partnerships are no silver bullet: An expanded governance model for critical infrastructure protection. International Journal of Critical Infrastructure Protection, 2(4), 179-187. https://10.1016/j.ijcip.2009.08.006

Ebrahim, A., Battilana, J., \& Mair, J. (2014). The governance of social enterprise: Mission drift and accountability challenges in hybrid organizations. Research in Organizational Behavior, 34, 81-100. https://10.1016/j.riob.2014.09.001

Hart, S. L., \& Quinn, R. E. (1993). Roles executives play: CEOs, behavioral complexity and firm performance. Human Relations, 46(5), 543-575.

Harrow, J., \& Phillips, S. D. (2013). Corporate governance and nonprofits. The Oxford Handbook of Corporate Governance ( $3^{\text {rd }}$ ed.). Oxford, England: Oxford Press

Jegers, M. (2009). Corporate governance in nonprofit organizations, Nonprofit Management and Leadership, 20(2), 143-164. https://10.1002/nml.246

Jones, R. (1987). Organization-client transactions and organizational governance structure. Academy of Management Journal, 30(2), 197-218. https://10.2307/256270

March, J. G., \& Simon, H. A. (1958). Organizations ( $2^{\text {nd }}$ ed.). New York, NY: John Wiley.

Mittal, S., \& Risco-Martin, J. L. (2017). Simulation-based complex adaptive systems. Simulation Foundations, Methods and Applications. https://10.1007/978-3-319-612664-5_6

Obolensky, M. N. (2014). Complex adaptive leadership: Embracing paradox and uncertainty. Farnham, UK: Gower Publishing Limited.

Renz, P. S. (2007). Project governance: Implementing corporate governance and business ethics in nonprofit organizations. New York: Physica-Verlag - Springer.

Schneider, M., \& Somers, M. (2006). Organizations as complex adaptive systems: Implications of complexity theory for leadership research. The Leadership Quarterly, 17(4), 351-365. https://10.1016/j.leaqua.2006.04.006

Siebart, P., \& Reichard, C. (2004). Corporate governance of nonprofit organizations. In A. Zimmer \& E. Priller (Eds.), Future of civil society (pp. 271-296). Wiesbaden: VS Verlag fur Sozialwissenschaften.

Speckbacher, G. (2008). Nonprofit versus corporate governance: An economic approach. Nonprofit Management and Leadership, 18(3), 295-320. https://10.1002/nml.187

Suarez de Vivero, J. L., Mateos, J. C. R., \& Florido del Corral, D. (2007). The paradox of public participation in fisheries governance. The rising number of actors and the devolution process. Journal of Marine Policy, 7(1), 1-7. https://10.1016/j.marpol.2007.06.005

Van Ees, H., \& Gabrielsson, J. (2009). Toward a behavioral theory of boards and corporate governance. Corporate Governance: An International Review, 17(3), 307-319. https://10.1111/j.1467-8683.2009.00741.x

Van Slyke, D. M. (2006). Agents or stewards: Using theory to understand the government-nonprofit social service contracting relationship. Journal of Public Administration Research and Theory, 17(2), 157-187. https://10.1093/jopart/mul012

Westphal, J. D. (1999). Collaboration in the boardroom: Behavioral and performance consequences of CEO-board social ties. Academy of Management Journal, 42(1), 7-24. https://10.2307/256871 
Prasetyo, A. H. 